distortion eliminated. The method involved considerable wastage of material, because ideal conditions at the two epochs could never be obtained, and there were also many possibilities of plates being spoilt by accidents of one sort or another. Schlesinger thoroughly investigated film distortions and proved. that their contribution to the final probable error was so small that the slight gain in accuracy was outweighed by the wastage of material and the other disadvantages of the method.

The observations in his short time at Yerkes enabled Schlesinger to determine twenty-eight parallaxes, with an average probable error of $\pm 0.013^{\prime \prime}$. In 1914, on the completion of the Thaw 30-in. photographic refractor, he started parallax work at Allegheny. In six years he determined 365 parallaxes and obtained plates for several hundred additional ones: the probable error of these parallaxes was about $\pm 0 \cdot 008^{\prime \prime}$. He also arranged a carefully planned scheme of co-operation between the seven Observatories of Allegheny, Dearborn, Greenwich, Leander McCormick, Mount Wilson, Sproul and Yerkes. In 1924 he published a "General Catalogue of Stellar Parallaxes", containing the parallaxes of 1,870 stars, all but a few of which were the outcome of this scheme of work.

But this advance in knowledge was restricted to the northern portion of the sky, and Schlesinger therefore began to consider the possibility of erecting a large refractor in the southern hemisphere to remedy the deficiency. In 1920 he was appointed director of the Yale Observatory and was able to bring these plans to fruition. A 26 -in. refractor of $36 \mathrm{ft}$. focal length was set up in the grounds of the University of the Witwatersrand, Johannesburg. The telescope and its housing were designed for the specific purpose of parallax determinations; as the observations are always obtained near the meridian, the motion of this telescope in right ascension is limited to about half an hour either side of the meridian, thus reducing considerably the cost of the installation. Co-operation with the Cape Observatory was also arranged, and the output of these two Observatories has been so considerable that the deficiency of knowledge of parallaxes of southern stars has been made good. The second edition of the "General Catalogue", published in 1935, contains trigonometrical parallaxes of about four thousand stars; including parallaxes determined by spectroscopic methods, the calibration of which is based on trigonometrical parallaxes, it gives the parallaxes of 7,534 stars. The "Catalogue" is not a mere compilation; it is based on a careful critical discussion of accidental and systematic errors to ensure that the probable errors assigned to the individual parallaxes are statistically correct.

Schlesinger's other main work was the determination of star positions from wide-field photographs. The basic ideas were to lighten the burden on the meridian observer, by restrieting meridian observations to the brighter stars, and to determine the positions of fainter stars more accurately as well as more economically by photography. Plates covering a large field were necessary to ensure that each plate should contain sufficient of the brighter stars to serve as reference points. Plans for a programme with a lens covering 25 square degrees were drawn up in 1915 and the positions of stars in three zones, each extending over $5^{\circ}$ in declination, were determined. Schlesinger then changed to a lens of $5 \cdot 6 \mathrm{in}$. aperture and a focal length of about 80 in., using plates measuring $48 \mathrm{~cm}$. by $58 \mathrm{~cm}$., covering an area of $10^{\circ}$ in declination and $14^{\circ}$ in R.A., with a scale of approximately $100^{\prime \prime}$ to $1 \mathrm{~mm}$. Somewhat later he substituted a more efficient lens of 5 -in. aperture, with plates $43 \mathrm{~cm}$. square, covering 112 square degrees. The wide-angle lens camera was mounted on the large refractor at Johannesburg for photographing the southern stars. The measurement and reduction of these large plates introduces a number of delicate technical problems which Schlesinger solved with consummate skill. As the programme proceeded, various modifications and refinements were introduced for greater convenience and accuracy. His latest catalogue, recently published, has probable errors of a catalogue position of $\pm 0.105^{\prime \prime}$ in each co-ordinate. Since 1925 the positions of some 77,000 stars have been published, a remarkable achievement for a single observatory with a small staff, and a tribute to the efficiency of Schlesinger's methods.

Schlesinger received the honorary degree of Sc.D. from the Universities of Pittsburg and Cambridge. He was elected an associate of the Royal Astronomical Society in 1914 and was awarded its Gold Medal in 1927. He was awarded the Valz Prize of the Paris Academy in 1926 and the Bruce-Medal of the Astronomical Society of the Pacific in 1929. His election as president of the International Astronomical Union for the period 1932-35 was a fitting climax to a career of solid achievement. He retired in 1941 but, though he suffered much ill-health in his last years, he continued his work on the zone catalogues to the end. He died on July 10, at the age of seventytwo. He was a man of great understanding, wise in counsel, loyal in friendship and trusted by all.

H. SPENCER JONES.

\section{Mr. C. V. B. Marquand}

Cecil Vrotor Boley Marquand, only son of Ernest David Marquand, author of a "Flora of "Guernsey", was born at Richmond, Surrey, on June 7, 1897. He was educated at Elizabeth College, Guernsey (1906-10), Lycée Henri IV, Paris (1910-11), Bedford School (1911-13), and Christ's College, Cambridge, where he took his B.A. in 1919, proceeding to M.A. in 1922. During the War of 1914-18 he served in the Machine Gun Corps, and held a commission in the Royal Tank Corps, from which he was invalided out.

On leaving Cambridge in 1919 Marquand was appointed research assistant in charge of investigations on Avena at the newly established Welsh Plant Breeding Station, Aberystwyth, and published a paper on "Varieties of Oats in Cultivation" in the second Cereal Bulletin of the Station. This was undoubtedly a very useful piece of work, and supplied keys for the identification of all the varieties that could be got together at that time. In 1923 Marquand was appointed assistant (a title since changed to botanist) in the Herbarium of the Royal Botanic Gardens, Kew, and at first continued work on the grasses, but was soon placed in charge of the Chinese section of the Herbarium, and wrote numerous papers on the flora of Eastern Asia, including revisions of the campanulaceous genus Cyananthus (1924), the Old World species of Buddleia (1930), and the gentians of China (1937). He was also interested in the genus Cotoneaster, many species of which are cultivated in Great Britain. He had charge of the Bryophyta (mosses and liverworts), a group which he had 
always found very attractive, but his other official work naturally left but little time for its study. $\mathrm{He}$ combined a passion for mountaineering with a great love of wild Nature, and was an enthusiastic fieldbotanist, many of his happiest days being spent in bryological holidays in the Alps, the Scottish Highlands, and North Wales. His ecological interests were reflected in a paper on the Bryophyta of Arctic-alpine associations in Wales (1922), and he continued to take a keen interest in genetics during his period at Kew, though he published nothing further on the subject.

Though Marquand was physically very vigorous, his constitution seems to have been permanently affected by his service during the War of 1914-18, and he retired from Kow in 1939 on account of illhealth. He then went to live in the island of Skye, where he was able to devote himself to field-work on the Lower Cryptogams. His tragic death last June on a boating expedition in search of a rare alga came as a great shock to his many friends. Generous, and incapable of a mean action, Marquand was a pleasant companion on a botanizing expedition, which his wide range of interests, not to mention his very decided views, helped to cheer and enliven.

T. A. Sprague.
WE regret to announce the following deaths :

Dr. H. G. Baynes, an authority on Jung's system of analytical psychology and author of "The Mythology of the Soul", on September 6, aged sixty-one.

Capt. F. O. Creagh-Osborne, C.B., formerly director of the Compass Department of the Admiralty, on September 1, aged seventy-six.

Sir Francis Fremantle, O.B.E., M.P., an authority on public health, on August 26, aged seventy-one.

Dr. Ales Hrdlička, head of the Division of Physical Anthropology in the U.S. National Museum from 1910 until 1942, on September 5, aged seventy-four.

Lady Lockyer, widow of the late Sir Norman Lockyer, founder of NATuRE, on September 9, aged ninety-one.

Dr. W. H. Metzler, formerly professor of mathematics in Syracuse University, on April 19, aged seventy-nine.

Sir James Morton, a pioneer in the British textile industry, on August 22, aged seventy-six.

Dr. Cecil Price-Jones, the authority on the sizes of blood cells, on August 29.

Prof. L. Susan Stebbing, professor of philosophy in the University of London (Bedford College), on September 11, aged fifty-seven.

\section{NEWS and VIEWS}

\section{Ophthalmological Research at Oxford}

As appeal for $£ 250,000$ has recently been launched by the University of Oxford to endow a Research Department in Ophthalmology. The only other university department of this character in Britain at the present time is the Tennant Research Institute at Glasgow, though the Royal Eye Hospital, in conjunetion with the Royal College of Surgeons, has recently founded a research chair in ophthalmology. In 1940 Lord Nuffield gave $£ 25,000$ to enable the University of Oxford to build a small temporary laboratory for the new reader in ophthalmology and to appoint a research biochemist. This laboratory has been open for a year and work on nutritional and other problems has been started. In 1941 the total blind population of England and Wales was 70,000. Although four and a half million pounds was spent on their welfare during that year, the amount spent on prevention was comparatively small. Apart from blindiness, it is perhaps not generally realized how widespread are defects of vision in the population. In 1937, nearly one sixth of the school children medically examined were found with "defective vision and squint". The children in London had a higher proportion of defects than those outside. Recent study of orthoptics justifies the hope of advancement in the relief of these defects in children and emphasizes the need for more work along these lines.

Advances in the science of nutrition have shown that a large amount of preventable blindness occurs in countries where the standard of life of the popula. tion is low. For example, deficiency in vitamin A leads to much blindness in children in Ceylon. Although such acute vitamin deficiencies do not occur in Europe, the effect of prolonged sub-optimal nutrition on the eyes must be investigated. Another problem to be examined is the question of illumination in factories and elsewhere. Defective illumination is responsible for many industrial accidents, as well as causing eye-strain among workers, resulting in diminished output. These examples show that what is needed at the present time is collaborative research between the ophthalmologist and research workers in experimental sciences. The department which the University of Oxford hopes to establish will provide facilities for such studies. Oxford is a peculiarly suitable home for such a department, as it already has an eye hospital which has a tradition of research, and collaboration between the medical and nonmedical sciences is well established.

\section{Research on Coal}

THE colliery owners of Great Britain will provide a further sum, of the order of half a million pounds, for coal research, in order to extend their existing programme, which itself involves the expenditure of $£ 1,000,000$ over the current five years. It will be recalled that the Parliamentary and Scientific Committee recently urged a great expansion of utilization research into coal derivatives, adding that although the work should be generously subsidized by the Government, it should be carried out by industry itself. The new programme now announced by the Mining Association of Great Britain relates to the development of processes for produeing hydrocarbons and hydrocarbon derivatives from coal, and to the treatment of coal generally as a chemical raw material. It will be put in operation immediately, and the colliery owners will themselves contribute $£ 400,000$ $£ 500,000$ towards its cost during the period ending with 1945.

\section{Coke and Coal Research}

THe investigations of Prof. H. L. Riley at King's College, Newcastle-upon-Tyne, and also those of Dr. R. A. Mott at the University of Sheffield, are concerned with problems affecting the hard coke industry, 